\title{
INTOXICAÇÃO POR COBRE EM OVINOS: REVISÃO DE LITERATURA
}

\author{
FIDELIS JUNIOR, Otávio Luiz ${ }^{1}$ \\ CADIOLI, Fabiano Antonio ${ }^{2}$ \\ MENDES, Luiz Claudio Nogueira ${ }^{3}$
}

\begin{abstract}
RESUMO: O cobre $(\mathrm{Cu})$ é um microelemento essencial aos mamíferos, entretanto, quando ingerido em altas quantidades, num período curto ou prolongado, pode provocar uma intoxicação severa. A habilidade de acumular $\mathrm{Cu}$ nos tecidos varia de acordo com as espécies e com as raças dentro da própria espécie, dentre as espécies acometidas, destacam-se a ovina, e em menor escala, canina, suína e bovina. A intoxicação aguda em ovinos é pouco frequente e pode ser decorrente da ingestão oral ou da administração parenteral de cobre. A intoxicação crônica é a principal forma de ocorrência desta enfermidade nesta espécie. A maioria dos ovinos acometidos é proveniente de manejo intensivo, os quais recebem dietas ricas em concentrados energéticos, e a ocorrência mais comum se dá quando estes animais ingerem misturas minerais destinadas a bovinos. A forma crônica caracteriza-se por três fases distintas: préhemolítica, hemolítica e pós-hemolítica. O resultado, tanto da forma crônica, como da aguda será a hemólise intravascular. O diagnóstico é realizado por meio do histórico, exame clínico e laboratorial e achados de necropsia. Entre os sinais clínicos destacam-se a icterícia e a hemoglobinúria. A terapia pode ser eficiente se for iniciada precocemente no decorrer do $1^{\circ}$ ao $2^{\circ}$ dia após o início da hemoglobinúria, sendo utilizado antídoto específico à base de tetratiomolibdato (TTM). O controle em rebanhos ovinos deve ser feito com rígidas medidas dietéticas, evitando se oferecer rações concentradas em concomitância com sais minerais que contenham altos teores de cobre.
\end{abstract}

Palavras-chave: $\mathrm{Cu}$. Intoxicação aguda. Intoxicação crônica. Ovelhas.

\section{CUPRIC POISONING IN SHEEP: LITERATURE REVIEW}

SUMMARY: Copper $(\mathrm{Cu})$ is an essential microelement for mammals, however, when ingested in high amounts in a short or prolonged period can cause severe intoxication. The ability to accumulate $\mathrm{Cu}$ in tissues varies with the species and breeds within species. Among species affected, we highlight the sheep, and to a lesser extent, canine, porcine and bovine. Acute intoxication in sheep is infrequent and may result from oral ingestion or parenteral administration of copper. The chronic intoxication is the main form in this specie. Most often affected sheep are from intensive management, which receive diets rich in energy, and the most common occurrence happens when animals ingest mineral mixtures for cattle. The chronic form of this disease is characterized by three distinct phases: prehemolytic, hemolytic and post-hemolytic. The result of either chronic or acute form is intravascular hemolysis. The diagnosis is made by history, clinical and laboratory examination and necropsy findings. Among the clinical symptoms stand out jaundice and hemoglobinuria. The therapy can be effective if started early, during the 1 st to 2 nd day after the onset of hemoglobinuria, being used specific antidote, tetrathiomolybdate (TTM). The control in sheep flocks should be done with strict dietary measures, avoiding offer concentrated concomitantly with minerals that contain high levels of copper.

Keywords: $\mathrm{Cu}$. Acute poisoning. Chronic poisoning. Ewes.

\footnotetext{
${ }^{1}$ Médico Veterinário Residente - FMV - Unesp - Campus de Araçatuba * Atualmente Mestrando em Medicina Veterinária - FCAV - Unesp - Campus de Jaboticabal

${ }^{2}$ Prof. Ass. Dr, de Clínica Médica de Grandes Animais - FMV - Unesp - Campus de Araçatuba.

${ }^{3}$ Prof. Adj. de Clínica Médica de Grandes Animais - FMV - Unesp - Campus de Araçatuba.
} 


\section{INTRODUÇÃO}

A intoxicação por cobre é uma enfermidade de grande relevância na espécie ovina, normalmente há uma grande diferença entre níveis deficientes e tóxicos de cobre $(\mathrm{Cu})$ para mamíferos. O consumo contínuo deste elemento em níveis maiores que as exigências dietéticas dos animais, levando a um acúmulo gradativo em vários locais, especialmente no fígado. A habilidade de acumular $\mathrm{Cu}$ nos tecidos varia de acordo com as espécies e com as raças dentro da própria espécie. Os ruminantes, especialmente os ovinos, são bastante sensíveis à intoxicação cúprica, pois a margem de segurança entre níveis normais e potencialmente tóxicos é muito pequena (ROSA; GOMES, 1982).

Além das biomoléculas orgânicas, os tecidos animais também possuem elementos inorgânicos que fazem parte dos tecidos e se encontram na proporção de 2 a $5 \%$ do peso total dos animais. Entre eses elementos estão os minerais que possuem funções essenciais tanto na estrutura de tecidos e biomoléculas, como no próprio metabolismo animal, participando como cofatores enzimáticos, ativação de ação hormonal, como responsáveis pela pressão osmótica e pelo equilíbrio acidobásico. Os minerais podem ser divididos em macroelementos e microelementos (GUERRA, 2008).

Os microelementos, ou também chamados elementos traços ou oligoelementos, estão presentes em quantidades pequenas no organismo e são expressos em $\mathrm{mg} / \mathrm{kg}$ ou ppm (partes por milhão) de peso vivo. Nestes se incluem o cobre, zinco, selênio, cobalto, ferro, flúor, manganês, iodo, molibdênio, cromo, arsênio, níquel, alumínio e vanádio (ORTOLANI, 2006).

$\mathrm{O}$ cobre $(\mathrm{Cu})$ é um microelemento essencial à sobrevida dos mamíferos, entretanto, quando ingerido em altas quantidades, num período curto ou prolongado, pode provocar uma intoxicação severa. Entre as espécies acometidas, destacam-se a ovina, e, em menor escala, a canina, a suína e bovina (ROSA; GOMES, 1982).

São consideradas fontes para intoxicação por cobre em ovinos: concentrados para cavalos, bovinos ou suinos, preparados para prevenção da deficiencia de cobre, pedilúvios contendo sulfato de cobre, pulverização de áreas pastadas por ovinos com pesticidas e fungicidas contendo cobre em sua formulação, poluição de rios e riachos com resíduos industriais de cobre e cama de frango utilizada como fertilizante de pastagens ou mesmo na alimentação dos animais (CHRISTODOULOPOULOS; ROUBIES, 2007).

\section{METABOLISMO}

O cobre é absorvido preferencialmente na sua forma divalente no intestino delgado. Na maioria das espécies, a taxa de absorção de cobre pelo intestino é baixa, sendo de 5-10\% em adultos e de 15-30\% em jovens. Essa taxa está regulada pela necessidade do organismo, pela forma química que se apresenta o elemento e pela quantidade de outros minerais que podem exercer efeitos antagônicos. O molibdênio (Mo) é um importante fator na absorção do cobre, níveis a partir de $10 \mathrm{ppm}$ de Mo no alimento causam interferência na absorção intestinal de cobre. A relação Cu/Mo ideal é de 6 -10 partes de cobre para 1 parte de molibdênio (GUERRA, 2008).

A absorção de cobre em ovinos como descrito anteriormente é regulada pela presença na dieta de alguns elementos, como o molibdênio, sulfato, ferro, zinco, etc. As necessidades diárias de cobre em ovino situam-se entre 4 a $6 \mathrm{mg} / \mathrm{kg}$ e as de molibdênio entre 0,3 a $0,5 \mathrm{mg} / \mathrm{kg}$. Os casos de intoxicação ocorrem quando há um acúmulo de cobre , principalmente no fígado, devido a absorção excessiva deste elemento pelo período de meses até um ano (ORTOLANI, 2006).65 
As fontes de cobre que foram responsabilizadas pela ocorrência de intoxicação em ovinos incluem sais com microelementos minerais (formulados para gado leiteiro), rações contendo mais de $20 \%$ de cama de frango seca, dietas ricamente suplementadas com resíduos de óleo de coco, pastagens fertilizadas com esterco de frango, forragens oriundas de pastagens com pomares frutíferos contaminados com fungicidas que contêm sulfato de cobre, parasiticidas para helmintos gastrointestinais e pedilúvios com sulfato de cobre, mourões de cerca tratados com fungicidas, cabos aéreos corroídos, sementes de grãos tratados com cobre e sais de cobre administrados por via parenteral para fins terapêuticos (comercializados para o tratamento de deficiência de cobre) (CARLSON, 2006).

A entrada de cobre no enterócito será facilitada quanto menor for a quantidade de metalotioneína presente nessa célula, que se liga fortemente ao cobre, retendo-o nesse local e diminuindo sua absorção. O cobre, após ser absorvido, deposita-se no fígado, que é o órgão-estoque. A partir do fígado, poderá ter destinos diferentes, dependendo do status orgânico do cobre. No tecido hepático, o cobre se liga a uma metaloproteína carreadora denominada ceruloplasmina, sendo transportado para todo organismo do animal. Em situações em que há superávit, o cobre se acumulará no interior dos hepatócitos, em diferentes organelas, tais como núcleo, mitocôndria, microssoma, lisossomo, etc. No entanto, quando o acumulo é exagerado, o cobre passa a depositarem-se principalmente nos lisossomos, praticamente dobrando o número dessas organelas nos hepatócitos (FERREIRA et al., 2008).

A eliminação do cobre ocorre principalmente através da via biliar. Para isso, este elemento deve se ligar a metalotioneína, produzida nos hepatócitos. Quanto menor a capacidade de ligação da metalotioneína com o $\mathrm{Cu}$, menor a capacidade de excreção do mesmo, predispondo a intoxicação. Nos ovinos, apenas 5\% do cobre hepático estão ligados a esta proteína (ORTOLANI, 2006).

\section{ETIOLOGIA}

A intoxicação por cobre pode ser aguda ou crônica. A primeira pode ser decorrente da ingestão de uma quantidade excessiva do elemento (20 a $100 \mathrm{mg} / \mathrm{kg}$ ) e a segunda da ingestão de doses diárias elevadas, acarretando o acúmulo do cobre. Ambas as formas são caracterizadas pelo acúmulo excessivo de cobre sérico ou hepático (BORGES, 2002; CARLSON, 2006; MÉNDEZ; RIET-CORREA, 2007).

Existe uma diferença marcante na suscetibilidade a esta enfermidade. Entre as espécies acometidas, destacam-se a ovina, e, em menor escala, a canina, a suína e bovina (ROSA; GOMES, 1982); dentre as várias raças ovinas, há uma tendência de as especializadas para carne serem mais predispostas que as fornecedoras de lã, bem como as raças consideradas nativas. As raças de corte tendem a absorver e reter mais cobre que as demais, apresentando, no entanto, menor necessidade deste elemento que as raças de lã, as quais utilizam para síntese de folículos pilosos. Dessa forma, entre as raças mais suscetíveis, citam-se North Ronaldsay, Texel, Suffolk, Ile-de-France e Welch Mountain; em situação intermediária, encontram-se Romney Marsh, Cheviot, Corriedale e Ideal; entre os menos suscetíveis podemos citar Santa Inês, Merino e Scottish Balckface (FERREIRA et al., 2008).

\section{Intoxicação Aguda}

A intoxicação aguda em ovinos é relativamente pouco frequente e pode ser decorrente da ingestão oral ou da administração parenteral de cobre. Uma única dose ou varias pequenas doses orais de cobre por um período curto pode provocar a intoxicação. $\mathrm{O}$ uso de amplas doses de preparados injetáveis contendo cobre para a prevenção ou o tratamento da deficiência de cobre leva frequentemente à intoxicação aguda 
(ORTOLANI et al., 2004).

Pode ser causada tanto pela administração de cobre por via oral ou então intravenoso, a primeira é causada pela ingestão acidental de uma só vez, de grande quantidade de sais de cobre. Injeções profiláticas de sais de cobre, especialmente os preparados aquosos, mais solúveis, serão bastante tóxicas, se for excedida a velocidade de administração recomendada. Não existem dados sobre a DM50, mas sabe-se que doses únicas de 20 a $110 \mathrm{mg} / \mathrm{kg}$ produzem intoxicação aguda em ovinos (RADOSTITS et. al., 2002).

Os quadros mais severos são verificados quando são ingeridas soluções com altas concentrações de cobre, formando assim a goteira esofágica e permitindo que esse microelemento se direcione rapidamente ao abomaso e aos intestinos (FERREIRA et al., 2008).

\section{Intoxicação Crônica}

Esta é, sem dúvida, a principal forma de intoxicação em ovinos. A maioria dos ovinos acometidos é proveniente de manejo intensivo, os quais recebem dietas ricas em concentrados energéticos. No entanto, este tipo de intoxicação também tem sido descrito em animais mantidos em condições extensivas, principalmente quando as pastagens estão contaminadas com altos teores de cobre (ORTOLANI et al., 2004).

Muitos alimentos concentrados ricos, de alto teor energético (por exemplo: farelo de trigo, glúten de milho, sorgo etc.) são razoavelmente ricos em cobre e pobres em molibdênio, enxofre e ferro, levanto à alta disponibilidade do cobre. Embora os teores de cobre sejam bem mais altos em concentrados proteicos (farelo de soja, de algodão etc.), as concentrações de elementos antagonistas também são altas, especialmente enxofre (FERREIRA et al., 2008).

A ocorrência mais comum de intoxicação por cobre em ovinos ocorre quando estes animais ingerem misturas minerais destinadas a bovinos. Diferentemente dos bovinos, o limite tóxico para ovinos é baixo, o que gera uma faixa relativamente estreita entre a necessidade e a toxicidade. Os suplementos minerais de bovinos apresentam, de modo geral, entre 1200 e $2000 \mathrm{mg}$ de cobre por kg de produto, bem acima dos suplementos para ovinos que apresentam em média $400 \mathrm{mg} / \mathrm{kg}$. A ingestão de produtos para bovinos por ovinos pode levar a um consumo de 30 a $60 \mathrm{mg} / \mathrm{kg}$ de matéria seca, que são valores bastante elevados para a espécie. Também, pode ocorrer não só pela administração incorreta ou exagerada desse composto mineral e sim por outras causas, tais como o consumo de plantas hepatotóxicas, drogas antifungicidas, drogas antiparasitárias, substâncias usadas para a erradicação de caracóis, por poluição industrial e pela relação desbalanceada de cobre/molibdênio no solo e pastagens. A intoxicação por cobre pode ser classificada de duas formas: aguda e crônica (GUERRA, 2008).

\section{PATOGENIA}

O resultado da forma crônica e aguda será a hemólise intravascular. A hemólise ocorrerá na intoxicação aguda, pois a quantidade de cobre ingerida será maior que o limiar possível de ligação com a metalotioneína dentro do hepatócito. O cobre livre acarretará morte das células intestinais devido à peroxidação dos lipídeos e da coagulação de proteínas. Ocorrerá um excesso na absorção de cobre, sobrepondo à capacidade do sistema de transporte (ceruloplasmina). Este cobre circulando livremente acarreta hemólise (devido à oxidação lipídica das membranas das hemácias) e lesão dos hepatócitos (BORGES, 2002). 
$\mathrm{Na}$ forma aguda os sais solúveis de cobre em concentrações elevadas coagulam as proteínas e a ingestão de grandes quantidades causa irritação intensa na mucosa do trato digestório e choque grave. Acentuada hemólise intravascular ocorre, quando o animal sobrevive por tempo suficiente (RADOSTITS et al., 2002).

$\mathrm{Na}$ forma crônica, caracteriza-se por três fases distintas: pré-hemolítica, hemolítica epóshemolítica. Na primeira delas, o cobre se acumula gradativamente no fígado e, em menor escala, nos rins, sem provocar o surgimento de sintomas característicos, a não serem nos últimos dez dias. Esse período pode variar de um mês até dois anos (FERREIRA et al., 2008).

A partir do momento em que o cobre satura o seu sistema de armazenamento, esse elemento pode tornar-se livre dentro do hepatócitos, levando-os a sofrerem necrose, conforme indicado pela liberação de certas enzimas hepáticas como a gama-glutamiltransferase (GGT), a aspartato aminotransferase (AST) e a sorbitol desidrogenase (SDH). Esse processo passa a ocorrer com mais intensidade nas últimas três semanas antes da crise hemolítica, exacerbando-se nos dois últimos dias. Nesse estágio, como há um grande número de hepatócitos necrosados, ocorre súbita liberação de cobre livre, lisozima e outros produtos para a corrente sanguínea (BORGES, 2002).

A crise hemolítica aguda ocorre em situações em que os animais que sofrem algum tipo de estresse fisiológico como viagens, confinamento, exposições, baixa na imunidade, fome. O excesso de cobre leva a uma oxidação na membrana do eritrócito, que fragilizado facilita a hemólise, a oxidação da hemoglobina pelo cobre, forma a meta-hemoglobina (não transportadora de O2) agravando ainda mais a crise hemolítica aguda (ORTOLANI, 2006).

É comum, num processo hemolítico, existir a diminuição de cerca de $70 \%$ das hemácias circulantes, provocando um quadro de anemia. A hemoglobina livre aumentará a produção de bilirrubina, a qual se acumula nos tecidos, resultando num acentuado grau de icterícia (FERREIRA et al., 2008).

Tanto o cobre como os radicais livres, lisozimas e hemoglobina são filtrados pelos rins. Portanto, no decorrer dos primeiros dias da crise hemolítica, a hemoglobinúria é notória. A passagem dessas substâncias provoca um intenso quadro lesivo nos glomérulos e túbulos renais. São danificados especialmente os túbulos contornados proximais, resultante em marcante insuficiência renal, sendo esta a principal causa mortis. A hemoglobina livre pode provocar obstrução dos néfrons, ocasionando acentuada oligúria. Essa substância, associada aos demais agentes supracitados, causa lesão severa de células tubulares, fazendo surgir hipostenúria, proteinúria, glicossúria, etc (FERREIRA et al., 2008).

Nem sempre a intoxicação crônica por cobre pode resultar em uma crise hemolítica, como é normalmente esperado, em vez disso, alguns animais podem morrer por uma doença hepática progressiva, a raça North Ronaldsay parece apresentar uma maior predisposição para apresentar este tipo de enfermidade (VILLAR et al., 2002).

\section{SINAIS CLÍNICOS}

Os sinais clínicos no quadro agudo são a apatia, anorexia, isolamento do rebanho, fraqueza, dor abdominal, diarreia, icterícia, hemoglobinúria e a morte em mais de 75\% dos casos (BORGES, 2002; CARLSON, 2006; MÉNDEZ; RIET-CORREA, 2007). Alguns animais apresentam bruxismo e vocalização, tendem a permanecer em decúbito esternal e em posição de auto-auscutação. São detectadas taquicardia, atonia ruminal e desidratação, sendo que quanto maior o grau de desidratação menor será a temperatura corpórea (FERREIRA et al., 2008). 
Em caso de intoxicação acumulativa, na fase pré-hemolítica, os sintomas são poucos ou nada evidentes e o ganho de peso é mantido. Quando há proximidade à crise hemolítica os animais deixam de ingerir concentrados e em seguida capim ou feno. No dia precedente à hemólise, os animais apresentam-se anoréxicos deprimidos. Na fase hemolítica o sinal mais evidente é a hemoglobinúria, que se mantém até o terceiro ou quarto dia da crise. Os animais mostram-se prostados e com grande apatia. Caso não sejam efetivamente tratados, é muito provável que a morte ocorra por volta do sétimo dia (FERREIRA et al., 2008).

Nos casos de intoxicação crônica apenas uma pequena perda de peso pode ser observada antes do quadro de hemólise. Após o episódio hemolítico, os quadros são muito semelhantes (BORGES, 2002).

Os parâmetros das grandes funções variam com a evolução do quadro. Nos primeiros três dias, os animais apresentam oligopnéia, taquicardia, hipertermia moderada e atonia ruminal. Em seguida, a frequência respiratória e a temperatura retal se restabelecem, enquanto os batimentos cardíacos podem elevar-se até o décimo quinto dia. Pode ocorrer diarreia catarral no decorrer da primeira semana (FERREIRA et al., 2008).

Segundo Rodrigues et al. (2004), os sinais clínicos apresentados pelos animais com intoxicação "crônica" por cobre foram apatia, ataxia, anorexia, perda de peso, icterícia, sintomas nervosos como pedalagem, urina com coloração escura (castanho) e morte. De um rebanho de 98 fêmeas reprodutoras, 45 vieram a óbito $(45,9 \%)$.

\section{PATOLOGia CLÍNiCA}

Os achados laboratoriais são os mais diversos possíveis, dependendo da fase evolutiva da intoxicação nos ovinos. Apenas no segundo dia que precede a crise hemolítica é que a cupremia se eleva, mantendo-se desse modo (entre 20 a $100 \mu \mathrm{M} / \mathrm{L}$ ) até o sexto dia. Os indicadores precoces de que está ocorrendo acúmulo hepático de cobre são as alterações detectadas nos níveis séricos das enzimas GGT e AST, sendo que a primeira aumenta sua atividade por volta do $28^{\circ}$ dia antes da crise hemolítica, enquanto a outra só apresenta elevação por volta de duas semanas depois (FERREIRA et al., 2008).

Em um relato de Christodoulopoulos e Roubies (2007), mesmo antes de ocorrer a crise hemolítica, animais que apresentavam níveis elevados de cobre na dieta, a enzima AST apresentava valores elevados em 70\% das amostras e mesmo depois de cessado o fornecimento excessivo de cobre na dieta (8 semanas) o nível dessa enzima em $15 \%$ das amostras ainda continuava elevado.

As variáveis mais importantes a serem monitoradas são os teores séricos de uréia e creatinina, que indicam o grau de insuficiência renal. Os exames de urina indicam hemoglobinúria, proteinúria, glicossúria e hipostenúria, baixa densidade e intensa quantidade de cilindros granulosos na primeira semana após a crise hemolítica (FERREIRA et al., 2008). O aumento dos níveis séricos de creatinina acompanha a crise hemolítica, devido ao bloqueio dos túbulos renais pela hemoglobina, resultando em necrose glomerular (CHRISTODOULOPOULOS; ROUBIES, 2007). O hematócrito cai rapidamente de 40 para $10 \%$ em 48 horas, durante um episódio agudo de hemólise. A metahemoglobinemia pode estar presente, devendo a urina ser examinada para a presença de hemoglobina (RADOSTITS et al., 2002).

\section{ACHADOS DE NECROPSIA}

Lesões macroscópicas estão ligadas a alterações na parede do abomaso e intestino delgado nos casos agudos, o conteúdo pode ter sua coloração enegrecida, indicativo de sangue digerido. Nos casos 69 
agudos e crônicos observa-se icterícia e um fígado friável e tumefeito. O rim pode também apresentar alteração em sua coloração devido à presença de hemoglobinúria (BORGES, 2002).

Castro et al. (2007), verificaram que todos os animais apresentaram icterícia profunda, com fígado apresentando uma cor amarela alaranjado e padrão acinar perceptível. Os rins apresentavam coloração marrom escuro tendendo para o preto. A análise histopatológica do fígado revelou necrose periacinar multifocal e retenção biliar grave. Os rins apresentavam nefrose hemoglobinúrica com a formação de hialinos e edema glomerular intenso.

\section{DIAGNÓSTICO}

O diagnóstico é realizado por meio do histórico, exame clínico e laboratorial e achados de necropsia. Entre os sintomas clínicos destacam-se a icterícia e a hemoglobinúria (TOKARNIA et al., 2010). A confirmação do diagnóstico é feita pela demonstração dos níveis elevados de cobre no sangue fígado, acrescida da evidência histológica de lesão hepática (RADOSTITS et al., 2002).

Conforme Humann-Ziehank et al. (2001), a determinação da concentração plasmática de $\mathrm{Cu}$ não é um parâmetro útil para o diagnóstico de intoxicação crônica durante a fase pré-hemolítica, este elemento apresenta uma diminuição significativa de sua concentração plasmática durante esta fase.

Segundo Roubies et al. (2008), a determinação da concentração hepática e renal de cobre é o indicador mais adequado para a confirmação de intoxicação cúprica acumulativa, sendo a determinação da concentração hepática a mais fidedigna dentre os dois. Já Villar et al. (2002), consideram os rins como a melhor ferramenta para o diagnóstico de intoxicação crônica por cobre, nos casos em que a crise hemolítica já tenha se estabelecido.

Dentre os diagnósticos diferencias para intoxicação cúprica podemos citar: Leptospirose, Hemoglobinúria pós-parto, Hemoglobinúria bacilar, intoxicação por plantas tóxicas, babesiose, anaplasmose, alguns casos de pasteurelose aguda (RADOSTITS et al., 2002).

\section{TRATAMENTO}

O tratamento para os envenenamentos agudos envolve grandes volumes de líquidos intravenosos, insuflação de oxigênio, e sangue integral, se o hematócrito estiver abaixo de $8 \%$. A terapia quelante com D-penicilamina (52 mg/kg diariamente durante 6 dias) e a administração oral diária de $100 \mathrm{mg}$ de molibdato de amônio e $1 \mathrm{~g}$ de sulfato de sódio anidro por ovino pode mobilizar efetivamente o excesso de cobre hepático. O tetratiomolibdato de amônio (50 a $100 \mathrm{mg}$ VO, duas vezes por semana) é utilizado para intoxicação por cobre (RADOSTITS et. al., 2002; CARLSON, 2006).

A terapia da intoxicação cúprica pode ser extremamente eficiente se for iniciada precocemente no decorrer do $1^{\mathrm{o}}$ ao $2^{\mathrm{o}}$ dia após o início da hemoglobinúria, e se for utilizado antídoto específico a base de tetratiomolibdato (TTM), na dose de $3,4 \mathrm{mg} / \mathrm{Kg}$ de peso vivo, este elemento tem a capacidade de quelar o cobre livre, bloqueando assim seus efeitos imediatos. O TTM também se liga ao cobre livre presente no complexo hemoglobina-lisossomo reduzindo ou praticamente inativando o efeito deste composto como agente nefrotóxico (SOARES, 2004).

\section{PROGNÓSTICO}

O prognóstico é variável e depende do tempo de evolução do quadro, do momento do início do tratamento e certamente do grau de insuficiência renal. Quando o tratamento é iniciado até o segundo dia 
de hemoglobinúria, o prognóstico é de regular a bom, mas a partir disso, passa a ser de regular a mal (FERREIRA et al., 2008).

\section{CONTROLE}

O controle em rebanhos ovinos deve ser feito com rígidas medidas dietéticas, evitando-se oferecer rações concentradas em concomitância com sais minerais que contenham altos teores de cobre. Existe a possibilidade de utilizar o tetratiomolibidato como preventivo para diminuir a quantidade de cobre estocado no fígado, aplicando-se duas a três doses do medicamento, esta alternativa só deve ser realizada em casos especiais, quando a frequência de intoxicação cúprica no rebanho é alta (FERREIRA et al., 2008).

Segundo Castro et al. (2007), para se evitar a intoxicação acumulativa por cobre deve-se: fornecer aos animais concentrados adequados para a espécie ovina com não mais de $10 \mathrm{ppm}$ de $\mathrm{Cu}$, evitar a suplementação de cobre para animais que recebam concentrado na dieta e à animais a pasto deve ser fornecer suplemento mineral contendo não mais que $0,4 \%$ de sulfato de cobre.

\section{CONSIDERAÇÕES FINAIS}

Com base na revisão de literatura pode-se concluir que, os ovinos são animais altamente susceptíveis a intoxicação por cobre, sendo a intoxicação acumulativa a mais comum de ocorrer. $\mathrm{O}$ consumo contínuo de pequenas doses desse elemento leva a um acúmulo do mesmo no fígado, até certo limite. Esse processo pode levar de semanas a meses. Após atingir esse limite o cobre é liberado, desencadeando uma série de alteração por todo o organismo, levando à morte na maioria dos casos.

Recomenda-se que fazendas, que porventura possuam bovinos e ovinos pastejando, as mesmas áreas precavenham-se contra o consumo, por parte de ovinos, de suplementos minerais com elevado conteúdo de cobre, destinados a bovinos.

\section{REFERÊNCIAS}

BORGES, A. S. Avaliação clínica e diagnósticos diferenciais em ovinos com icterícia e mortalidade. In: SIMPÓSIO PAULISTA DE OVINOCULTURA, 6. Anais... p.51-58, 2002.

CARLSON, G. P. Moléstias dos sistemas hematopoético e hemolinfático. In: SMITH, B. P. Medicina interna de grandes animais. 3.ed. Barueri: Manole, 2006, cap.35, p.1061-1062.

CASTRO, M. B. et al. Copper toxicosis in sheep fed dairy cattle ration in São Paulo, Brazil. Arquivo Brasileiro de Veterinária e Zootecnia, v.59, n.1, p.246-249, 2007.

CHRISTODOULOPOULOS, G.; ROUBIES, N. Diagnosis and treatment of copper poisoning caused by accidental feeding on poultry litter in a sheep flock. Australian Veterinary Journal, v.85, n.11, p.451453, 2007.

FERREIRA, M. B.; ANTONELLI, A. C.; ORTOLANI, E. L. Intoxicação por cobre, selênio, zinco e cloreto de sódio. In: SPINOSA, H. de S.; GÓRNIAK, S. L.; PALERMO-NETO, J. Toxicologia aplicada a medicina veterinária. Barueri: Manole, 2008, Cap.24, p.665-697.71 
GUERRA, T. A. Cobre: deficiência e intoxicação. Seminário apresentado na disciplina Transtornos metabólicos dos animais domésticos. Programa de Pós-Graduação em Ciências Veterinárias da Universidade Federal do Rio Grande do Sul, 2008. Disponível em:

http://www.ufrgs.br/lacvet/restrito/pdf/cobre.pdf. Acesso em 10 set. 2012.

HUMANN-ZIEHANK, E. et al. Long-term observation of subclinical chronic copper poisoning in two sheep breeds. J Vet Med A Physiol Pathol Clin Med, v.48, n.7, p.429-439, 2001.

MÉNDEZ, M.C; RIET-CORREA, F.. Intoxicação por cobre. In: RIET-CORREA, F.. et al. Doenças de ruminantes e equinos. 3.ed., São Paulo: Varela, 2007, Cap.1, v.2. , p. 62-69.

ORTOLANI, E. L. Macro- e Microelementos. In: SPINOSA, H. L.; GÓRNIAK, S. L.; BERNARDI, M. M. Farmacologia aplicada à medicina veterinária. 4.ed., Rio de Janeiro: Guanabara Koogan, 2006, Cap.59, p.750-761.

ORTOLANI, E. L.; ANTONELLI, A. C.; de SOUZA SARKIS, J. E. Acute sheep poisoning from a copper sulfate footbath. Vet Human Toxicol, v.46, n.6, p.315-318, 2004.

RADOSTITS, O. M. et al. Doenças Causadas por Substâncias Químicas Inorgânicas e Produtos Químicos Utilizados na Fazenda. In: Clínica Veterinária: um tratado de doenças dos bovinos, ovinos, suínos, caprinos e equinos. 9.ed., Rio de Janeiro: Guanabara Koogan, 2002, Cap. 31, p.1417-1471.

RODRIGUES, N. C. et al. Chronic copper poisoning in sheep fed with poultry litter and citrus pulp. Ars. Veterinaria, v.20, n.2, p.175-179, 2004.

ROSA, I. V.; GOMES, R. F. Intoxicação crônica por cobre em ovinos. Embrapa Gado de Corte, COT n.14, Campo Grande/MS, 1982.

ROUBIES, N. et al. A retrospective study of chronic copper poisoning in 79 sheep flocks in Greece (1987-2007). Journal of veterinary Pharmacol Therap, v.31, n.2, p.181-183, 2008.

SOARES, P. C. Efeitos da intoxicação cúprica e tratamento com tetratiomolibdato sobre a função renal e o metabolismo oxidativo de ovinos. 2004. $116 \mathrm{f}$. Tese (Doutorado) Faculdade de Medicina Veterinária e Zootecnia. Universidade de São Paulo.

TOKARNIA, C. H. et al. Intoxicação por cobre. In: produção. Rio de Janeiro: Helianthus, 2010, Cap.7, p.103-109.

. Deficiências minerais em animais de

VILLAR, D. et al. Retrospective study of chronic copper poisoning in sheep. An. Vet. (Murcia), v.18, p.53-60, 2002. 
